\title{
Who And What Influences Choice Of University? Student And University Perceptions.
}

Timothy C. Johnston, Murray State University, USA

\begin{abstract}
Emerging peer-to-peer communication via social media, and the role of influential peers, is changing the way that marketers communicate with prospects. The model is changing from a sender-receiver model to one that includes influential peer-to-peer and receiver-to-sender communication. This research examines this phenomenon in the context of student choice of a university. What is the relative influence that various sources of information have on students' choice of university? How does the influence of friends and family members compare to the influence of non-personal media? How do high-touch tools like campus visits compare to hightech tools such as social media sites? Results of a survey of students showed that parents, along with other family and friends, were the most influential sources of information. Outside of personal contacts, a student's visit to campus was highly influential. Surprisingly, social media was not rated as highly influential compared to traditional media. Results of a second survey of university employees generally predicted student responses well, although employees underestimated the influence of university representatives (faculty members, staff, and coaches) and underestimated the impact of a visit to campus as sources of information for prospective students.
\end{abstract}

Keywords: Marketing, consumer choice behavior, higher education marketing, social media, influentials, influencers, word-of-mouth

\section{INTRODUCTION}

niversities are challenged to attract good students to enroll each year, in competition with other
universities. Higher education marketing, also called enrollment management, is a big business and
itself an academic field.

One task of higher education marketers is to communicate to prospective students the benefits of enrolling. There is a perception among higher education marketers that the traditional means of communication, such as brochures and college fairs, are giving way to newer social media methods, including websites, FaceBook, YouTube, Twitter, etc. (Marklein, 2009).

Emerging peer-to-peer communication via social media, and the role of influential peers, is changing the way that marketers communicate with prospects. The model is changing from a sender-receiver model to one that includes influential peer-to-peer and receiver-to-sender communication. Social media technology has made peer-topeer contact easier, and hence increased the influence of peers on decision makers (peers here means Internet users, not necessarily demographic peers). This research examines this phenomenon in the context of student choice of a university.

What is the relative influence that various sources of information have on students' choice of university? How does the influence of friends and family members compare to the influence of non-personal media? How do high-touch tools like campus visits compare to high-tech tools such as social media sites? 
This research examines data from students who rated the influence of various sources of information on their decision to enroll at a university. The research also considers data from a survey of university employees who predicted the responses of students. The methodology and results of two survey are discussed next. The paper concludes with potential implications for communicating with prospective students.

\section{LITERATURE REVIEW}

During the process of telling consumers about products, marketers realized that consumers were talking and listening to each other about the products. The listeners found the information from their peers more credible than information from the company. And not all talkers were created equal. The opinions of some consumers were highly credible and had a great impact on other consumers.

Berry \& Keller (2003) termed these people the Influentials, and argued based on survey data that the opinions of about one in ten Americans had a great deal of influence on the opinions and behavior of the other 9 of their peer consumers. Because Influentials try new products and services early, and have strong opinions and are not shy about sharing them, marketers should target special communications to these people. Positive recommendations from the Influential $10 \%$ are spread by word-of-mouth to the impressionable remaining $90 \%$ of the market.

Gillin (2007) updated the idea of Influentials with a discussion of what he termed the New Influencers. Gillen's Influencers use social media tools such as podcasts, FaceBook, Twitter, and especially blogs to communicate with consumers. Gillen focused less on the demographics and lifestyles of Influentials and more on their goals and motivations for speaking out in the social media sphere. Social media norms, such as transparency (e.g. revealed biases and potential conflicts-of-interest), are easily breached by overtly commercial messages.

Researchers have explored the importance of word-of-mouth communication for a long time. Brown \& Reingen (1987) listed early research on the positive effects of word-of-mouth communication on household goods and food products (Katz \& Lazarsfeld, 1955), automobile services Engel, Blackwell, \& Kegerreis, 1969), and the selection of a physician (Feldman \& Spencer, 1965).

They also studied the relative influence of strong and weak social ties between people. Strong ties (between members of a family or group) were perceived as more influential than weak ties, and they were more likely to be utilized as sources of information for related goods. Weak ties allowed information to travel from one subgroup to another (Brown \& Reingen, 1987).

Higher education marketing is an industry unto its own with conferences, professional organizations, consultants, and academic and practitioner journals. It is beyond the scope of this paper to review the field, especially the models for college choice. The choice of college can be a complex choice that includes several sequential decisions (Dawes \& Brown, 2005). The choice may involve multiple decision makers (Broekemier \& Seshadri, 2000), and multiple attributes. It may be fraught with emotion as well as rational choice processes.

Much research has focused on the attributes of the choice alternatives. Relatively little research has been done on the sources of influential information (for example, Armstrong \& Lumsden, 2000). Recent research has shown that university admission offices are using social media more, such as social media sites and blogs. About $85 \%$ of colleges reported using social media in recruiting in 2008, compared to 51\% in 2007 (Mattson \& Barnes, 2009).

This research explores the influence of sources of information for university choice, where some sources reflect strong social ties (parents) and others are non-personal sources of information, such as a university website.

\section{METHODOLOGY}

The student data were collected with a paper survey. The questions comprised about $20 \%$ of the content of a survey instrument, and the remaining items were part of a different project and were unrelated to this research. 
The author generated a list of items based on personal judgment, and the list was revised after a pretest with 20 respondents.

Generally respondents were given the survey form and asked to complete it and return it while the field researcher waited. Responses were anonymous, with no identifying data. Field researchers chose the respondents at their convenience from students on a university campus.

Table 1 has demographic data for the population of undergraduate students at the University (approx. 6400) and sample ( $\mathrm{n}=475)$. The mean age of the sample (21.5 years) is very close to the mean age of the population (21.8 years). This reflects the population of primarily traditional full time resident undergraduate students who began as freshman soon after graduating from high school.

There were proportionately more male respondents in the sample (49.7\%) than in the population (41\%), with corresponding underrepresentation of females. There were proportionately more juniors and seniors respondents in the sample (25\% and $45 \%)$ than in the population (22\% and 33\%), with corresponding underrepresentation of freshman and sophomores.

While the sample was not chosen by a method to make it strictly representative of the University much less the wider population of university students, the profile of the sample is characteristic of the University population and not unlike other regional public universities in the United States.

Table 1: Characteristics of student population and sample

\begin{tabular}{|l|c|c|}
\hline & Population & Sample \\
\hline Age & 21.8 years & 21.5 years \\
\hline Male & $41 \%$ & $49.7 \%$ \\
\hline Female & $59 \%$ & 50.1 \\
\hline Freshman & $22 \%$ & $14 \%$ \\
\hline Sophomore & $20 \%$ & $16 \%$ \\
\hline Junior & $22 \%$ & $25 \%$ \\
\hline Senior & $33 \%$ & $45 \%$ \\
\hline
\end{tabular}

\section{SURVEY RESULTS}

Respondents were asked: "What sources of information influenced your decision to enroll at (University)? Please rate each of the following sources of information on a scale of 0 to 6 , where $0=$ zero influence to $6=$ extremely high influence. Do not leave any blank." (The word University here replaces the name of the university in the study). The sources of information are listed in Table 2, in the order presented in the survey.

The survey of students yielded 475 respondents and 2677 non-zero ratings. The task of rating the influence of 16 sources of information proved to be challenging to the respondents, perhaps partly because the task came at the end of answering additional unrelated questions. The responses reflected apparently thoughtful ratings of a subset of items with the balance of items being rated at zero influence.

As a practical matter, a zero rating of an item was more a reflection of an unrated item than a rating of zero influence. For example, it is difficult for a respondent to rate the relative influence of a campus visit if he or she did not visit the campus, hence a zero rating is equivalent to a "not applicable" response.

An analysis was conducted with all ratings, including zeros. A subsequent analysis of only non-zero ratings yielded mean ratings with better face validity (e.g. greater means for items with high ratings). For example, the top mean rating for an item, not including zero ratings, was 3.85 on a scale where 6 equals "extremely high influence." This has greater face validity than the analysis that included zero ratings, in which the highest-rated source of income had a mean value of 2.45 influence. Both analyses yielded similar item rankings. 
Therefore, the analysis considers only rated items. In other words, the zero ratings are treated as not rated, and the responses one through six are used to calculate the mean values. The sources of information and mean ratings of influence, for rated items only and ignoring zero responses, are listed in Table 2.

Table 2: Sources of information and mean influence ratings on choice of university

\begin{tabular}{|l|c|c|c|}
\hline \multicolumn{1}{|c|}{ Source of information } & Number of ratings & $\begin{array}{c}\text { Influence rating } \\
\text { (mean) }\end{array}$ & Student Rank \\
\hline mother influence & 300 & 3.84 & 2 \\
\hline father influence & 270 & 3.76 & 4 \\
\hline other family member influence & 210 & 3.57 & 6 \\
\hline student friend in high school & 223 & 3.69 & 5 \\
\hline student friend at (University) & 225 & 3.73 & 8 \\
\hline high school teacher/coach/counselor & 190 & 3.45 & 1 \\
\hline (University) faculty/staff/coach & 171 & 3.85 & 12 \\
\hline (University) Student Ambassador & 76 & 2.91 & 9 \\
\hline attended (University) sport event(s) & 132 & 3.16 & 3 \\
\hline other visit to (University) campus & 247 & 3.81 & 11 \\
\hline Facebook/MySpace/YouTube & 79 & 2.91 & 13 \\
\hline (University) website & 187 & 2.84 & 15 \\
\hline other website & 20 & 2.70 & 10 \\
\hline paper mail from (University) & 151 & 2.99 & 14 \\
\hline e-mail from (University) & 115 & 2.83 & \\
\hline
\end{tabular}

Personal sources of information, including family and friends, are among the top-rated sources of influence. The data show that five of the top seven influential sources of information were family members and friends.

Mean rating of "mother influence" was ranked number $2(n=300 ; 3.84)$ and "father" influence was ranked number $4(\mathrm{n}=270 ; 3.76)$. "Student friend" at the University and from high school were ranked number $5(\mathrm{n}=225$; $3.73)$ and number $6(n=223 ; 3.69)$, respectively. "Other family member" ranked number $7(n=210 ; 3.57)$ in influence.

This is consistent with the consumer behavior concept of primary reference group: "We may have direct and extensive contact with some reference groups like our immediate circle of friends or family but less contact with our former high school classmates. Reference groups with which we have considerable contact tend to exert the greatest influence" (Hoyer \& MacInnis, 2007, p. 403).

The big surprise in this analysis is that the top-rated source of information is "University faculty/staff/coach," with a mean 3.85 influence rating. The data suggest that a coach or faculty or staff member had a big influence on the 171 people who rated this item. One caveat is that the respondents were chosen at the convenience of student field researchers, and 5 of the 20 researchers participated in intercollegiate athletics. Student athletes are perhaps overrepresented as respondents in the sample.

One is led to conclude that for these students the university coach is more influential than Mom! Upon further attention one sees that the mean ratings of influence are too close to call, being separated by only .01, and the greater number of students who rated "mother influence" (300 versus 171 for University faculty/staff/coach) gives Mom the edge in influence.

On the other hand, "university faculty/staff/coach" influence was rated number one, much higher ( $\mathrm{n}=171$; 3.85) than "high school teacher/coach/counselor" at number $8(n=190 ; 3.45)$. Traditionally, high school employees are seen as accessible and influential to prospective students, and are the target of more promotion, than are university employees. 
These items represent people who are not in a student's family, but can still be considered members of the student's primary reference group due to personal acquaintance and face-to-face interaction. The roles of these people in the lives of students make them potential opinion leaders as well. "Opinion leaders have some position, expertise, or firsthand knowledge that makes them particularly important sources of relevant and credible information, usually in a specific domain" (Hoyer \& MacInnis, 2007, p. 403). For prospective students who live in the geographic region, there is a good chance these people are alumni or alumnae of the University as well.

The unusual item in the top half is "other visit to University campus." This item is the third-highest rated (3.81) source of influence and the only non-personal item among the highest rated items. (The name includes "other" because it appears after "attended (University) sport event(s)" on the survey instrument.) The finding that 247 out of 475 respondents chose to rate this item, and gave it a mean rating between that of Mother and Father, is a testament to the influence of a campus visit.

The high rating of a visit to campus shows the influence of physically visiting campus to a prospective student. It also reflects the efforts of this particular university to bring high school students to campus for recruiting days, open houses, and conferences for student groups (FFA, Future Business Leaders of America, and DECA). High-touch contact was more influential than high-tech (e.g. Internet) sources of information for this sample.

Ranked number nine was "attended University sport event(s)" ( $\mathrm{n}=132 ; 3.16)$. This was somewhat surprising given the many opportunities for students in the geographic region to attend basketball and football games, in particular. There is a perception that sports teams are important recruiting tools for students in general. The survey did not attempt to measure the influence of television or other media coverage of sporting events.

The bottom half of the rankings is comprised mainly of non-personal sources of information. The item "paper mail from University" was ranked number $10(\mathrm{n}=151 ; 2.99)$, and was followed closely by "Facebook/ MySpace/YouTube" at number $11(\mathrm{n}=79 ; 2.91)$. What is surprising is that paper mail from the University remains an important source of information, give the widespread opinion that print media in general is being dominated by digital media (Garfield, 2009).

One must keep in mind that the modal high school graduation year of respondents was 2005 (see Table 3). Use of social media such as Facebook, MySpace, YouTube, and recently Twitter has grown rapidly in the years since about 2006. The University began formally using YouTube and Twitter as communication tools in 2009. Social media as information sources may be more influential to future students than it was to students who were choosing a university in 2005 .

Table 3: High School graduation year of students

\begin{tabular}{|c|c|c|}
\hline Graduation Year & Frequency & Percent \\
\hline $1975-2001$ & 24 & 2 \\
\hline 2002 & 16 & 3 \\
\hline 2003 & 21 & 5 \\
\hline 2004 & 32 & 19 \\
\hline 2005 & 129 & 17 \\
\hline 2006 & 112 & 10 \\
\hline 2007 & 69 & 9 \\
\hline 2008 & 57 & 100 \\
\hline total & 460 & \\
\hline
\end{tabular}

The item "University Student Ambassador" reflected the influence of Student Ambassadors on prospective students, and was ranked number $12(\mathrm{n}=76 ; 2.91)$, essentially a tie with "Facebook/ MySpace/YouTube." A prospective student may have come in contact with a Student Ambassador on a campus visit, where the Ambassador served as a tour guide. Student Ambassadors represent the University at a variety of events including career fairs, high school visits, college fairs, etc. The University also has sent Ambassadors on recruiting trips to high school campuses. 
The list of information sources contains three additional Internet-related items that were tied in the ratings. "University website" ranked at number $13(\mathrm{n}=187 ; 2.84)$ and "e-mail from University" ranked at number $14(\mathrm{n}=115$; 2.84). "Other website" received relatively few ratings and was ranked number $15(\mathrm{n}=29 ; 2.70)$. The opportunity to write-in a URL did not yield any one influential website. Here again, the current interest in online communication suggest that these items should be rated higher.

The survey instrument included an open-ended item "other" that received a relatively high mean rating, but an analysis of the responses did not yield any consensus on an additional source of information. Many write-in responses to the "other" question were related to reasons a student chose the University rather than a source of information (e.g. received a scholarship). Therefore the "other" item is omitted from the rankings and discussion.

In conclusion, the student survey found the surprising results that university faculty, staff, and/or coaches are highly influential, ranked up with mother and father. Also, a visit to campus is the only non-personal source of information that is ranked as a rival to personal sources of information. Internet and new media sources of information do not dominate traditional material such as paper mail.

\section{SECOND STUDY: UNIVERSITY EMPLOYEE SURVEY}

Universities are challenged to attract good students to enroll each year, in competition with other universities. Do the university employees-administrators, faculty members, and staff-have an accurate perception of what sources of information are influential to prospective students?

In a second study, university employee data were collected with a paper survey. Generally respondents were given the survey form and asked to complete it and return it by campus mail to the investigator. Responses were anonymous, with no identifying data.

University administrators, faculty members, and staff (university employees) were asked: "Please predict the results of student ratings by RANKING the 6 top-rated sources of information, where 1 is highest rated source of information, 2 is the second highest rated source of information, etc. through 6 as the sixth highest rated source. Use each number 1 though 6 only once, and leave the unranked items blank."

The survey of university employees yielded 190 respondents. A breakdown of the respondents by university role is found in Table 4. An "Adminstrator" is an employee who works half-time or more in administration. "Faculty" includes tenured, tenure-track, and non-tenure-track faculty members. "Staff" includes employees not providing instruction and not considered "professional" staff.

Table 4: Characteristics of university employee population and sample

\begin{tabular}{|l|c|c|}
\hline & Population & Sample \\
\hline Administrator & $23 \%$ & $14 \%$ \\
\hline Faculty & $37 \%$ & $49.0 \%$ \\
\hline Staff & $40 \%$ & $36 \%$ \\
\hline Other & 0 & $1 \%$ \\
\hline Total & $100 \%$ & $100.0 \%$ \\
\hline
\end{tabular}

A ranking task was used with university employees to avoid the ambiguity of zero ratings in the student survey discussed previously. The university employee rankings are compared to student rankings in Table 5. The data in the Student Rank column is based on the mean ratings of the items. 
Table 5: Sources of information and mean influence ratings on choice of university, student and university employee (administrators, faculty and staff) responses

\begin{tabular}{|l|c|c|c|c|}
\hline \multicolumn{1}{|c|}{ Source of information } & $\begin{array}{c}\text { Student responses } \\
(\mathbf{n = 4 7 5})\end{array}$ & $\begin{array}{c}\text { Student } \\
\text { Rank }\end{array}$ & $\begin{array}{c}\text { Employee } \\
\text { responses } \\
(\mathbf{n = 1 9 0})\end{array}$ & $\begin{array}{c}\text { Employee } \\
\text { Rank }\end{array}$ \\
\hline mother influence & 300 & 2 & 160 & 1 \\
\hline father influence & 270 & 4 & 147 & 2 \\
\hline other family member influence & 210 & 7 & 66 & 5 \\
\hline student friend in high school & 223 & 6 & 129 & 3 \\
\hline student friend at (University) & 225 & 5 & 118 & 4 \\
\hline high school teacher/coach/counselor & 190 & 8 & 61 & 6 \\
\hline (University) faculty/staff/coach & 171 & 1 & 26 & 11 \\
\hline (University) Student Ambassador & 76 & 12 & 29 & 14 \\
\hline attended (University) sport event(s) & 132 & 9 & 123 & 7 \\
\hline other visit to (University) campus & 247 & 3 & 41 & 10 \\
\hline Facebook/ MySpace/YouTube & 79 & 11 & 45 & 8 \\
\hline (University) website & 187 & 13 & 4 & 12 \\
\hline other website: & 20 & 15 & 21 & 15 \\
\hline paper mail from (University) & 151 & 10 & 11 & 9 \\
\hline e-mail from (University) & 115 & 14 & & 13 \\
\hline
\end{tabular}

Only the ordinal rank data from Students and Employees are compared. No statistical tests of differences between mean ratings (t-test) or tests of difference between the ranking patterns within item rankings (chi-square) are presented. Employees were constrained to rank only six items, and to use each rank (1 to 6) only once. Students were free to rate any or all items and to use each rating score multiple times. The differences between the data generated by the rating and ranking tasks make statistical tests difficult to interpret. Therefore the discussion of findings will focus on the larger differences in rankings that were generated with the rating and ranking tasks by this sample of students and employees.

Students and university employees agree on rankings of the influence of sources of information more than they disagreed. The rankings on 10 items differed by only one or two places in the order. The surprising differences in rankings were found with the influence of "University faculty/staff/coach" and "visit to university campus."

Students ranked "University faculty/staff/coach" number one, whereas compared university employees predicted an influence rank of 11. This is a big gap and suggests a lack of awareness among university employee as to the influence of university faculty members, staff, and coaches on prospective students. Unfortunately due the combined category it is not possible to tease out the relative influence on prospects of various university representatives. Also, as mentioned earlier, student athletes are perhaps overrepresented as respondents in the sample.

Regarding "visit to university campus," student responses yielded a rank of 3, compared to the university employee mean rank of 10 . This is also a big gap in ranking, and may indicate that university employees underestimate the impact that a visit to campus makes on prospective students.

The rankings by university employees generally mirrored those of students when they estimate personal sources of information (parents, friends) as having a greater degree of influence than non-personal sources of information. It is somewhat of a surprise that university employees ranked new media tools (Facebook, MySpace, and YouTube) at 8, higher than the student-reported rank of 11. This disparity may reflect the nascent nature of new media at the time that current students choose a university, as compared to the current emphasis on new media as means to communicate with prospective students.

In conclusion, university employees predicted student ranking of sources of information by influence fairly accurately. The gaps appeared where university employees perhaps underestimated the influence of university representatives (faculty members, staff, coaches) and underestimated the impact of a visit to campus by a prospective student. 


\section{LIMITATIONS}

Student respondents were asked to access their memory about a complex decision process that took place typically from one to four years prior to the survey. One should be aware of the limits of memory as well of the lack of self-awareness for a complex decision; both can be sources of error in the data. Field researchers chose the respondents at their convenience from students on one university campus. Employee respondents were asked predict the student rankings and the limitations of the employee to access these data are considerable.

The data were limited to current university students who were at one time prospective students who chose the university. Prospective students who considered but did not choose the university were not in the sampling population. Richins (2003) showed that dissatisfied customers share negative word-of-mouth, which could deter prospective students from choosing the university. The sources or effects of negative influence were not considered in this study.

\section{LESSONS LEARNED}

Not surprisingly, personal sources of information were important, and more so than non-personal sources. Parents led the list, and a university should communicate with both. If you have to communicate with only one influencer, persuade the mother! Parents may have a role in the decision-making group that goes beyond their influence as a source of information. University representatives (faculty, staff, coach) have a surprisingly high degree of influence. The high school staff member—not so much.

University employees predicted student ranking of sources of information by influence fairly accurately. The gaps appeared where university employees perhaps underestimated the influence of university representatives (faculty members, staff, coaches) and the impact of a visit to campus by a prospective student. Perhaps the university should target communication to its internal "influencers" at least as much as the less-influential high school counselors.

Among non-personal sources of information, a visit to campus stands far above all others. It appears that one surefire way for a university to break through the clutter of brochures, emails, and websites to reach a prospective student is to host him or her on campus. A campus visit strategy is somewhat expensive and challenging to scale up. Is there a substitute? Can a university approximate the experience with media-rich, social, interactive online experiences?

Paper mail held its own in this study, when its influence was compared to that of social media tools, university website and email. The influence ratings of all media tools were lower than that of personal sources of information and campus visits.

The use of social media is growing rapidly. The influence of social media as a source of information is probably underestimated in this study. The use of social media by admissions increased rapidly from 2007 to 2008, and this study was based on decisions mostly made in about 2005 .

These exploratory findings raise questions for future research and potentially for the promotion strategy of the university. If family members and friends are the most influential sources of information to students, then what are the influential sources of information to family and friends? Is the university communicating with family members of prospective students, or is the university leaving this important channel of influence to chance?

The use of social media tools is growing. What social media New Influentials have the "ear" of prospective students? Is the university's online voice being heard, or is it being drowned out by online peers? Again, is the university part of the conversation or is it leaving this important channel of influence to chance? 


\section{CONCLUSION}

For higher education marketers, the findings underscore the need to communicate not only with students, but also with parents and University representatives. These people are influential sources of information for students.

The highest-rated non-family source of information was a visit to the campus. While a campus visit is a relatively expensive means of communication, it has an outsized impact on prospective students.

Among non-personal sources of information, the influence of paper mail was comparable to that of social media tools, although the university decisions studied were made prior to recent popular gains in the use of social media. Marketers should consider that social media are not at present a replacement for traditional media, but rather a supplement. Universities are faced with adapting to new ways of communicating with prospective students and their influencers, while maintaining the personal connections that are so influential to the choice of university.

Emerging peer-to-peer communication via social media, and the role of influential peers, will continue to change the way that higher education marketers communicate with prospective students. This mirrors general changes in the communication model for marketers, from a sender-receiver model to one that includes influential peer-to-peer and receiver-to-sender communication.

\section{REFERENCES}

1. Armstrong, Jami J. \& D. Barry Lumsden (2000). Impact of Universities' Promotional Materials on College Choice. Journal of Marketing For Higher Education, 9:2, 83-91.

2. Barnes, Nora Ganim \& Eric Mattson (2009). Social Media and College Admissions: The First Longitudinal Study. Center for Marketing Research. Retrieved May 5, 2009 at http://www.umassd.edu/cmr/studiesresearch/mediaandadmissions.pdf

3. Berry, Jon \& Ed Keller (2003). The Influentials: One American in Ten Tells the Other Nine How to Vote, Where to Eat, and What to Buy. NY:Free Press

4. Broekemier, Greg M. \& Srivatsa Seshadri (2000). Differences in College Choice Criteria Between Deciding Students and Their Parents. Journal of Marketing For Higher Education, 9:3, 1-13.

5. Brown, Jacqueline Johnson and Peter H. Reingen (1987). Social Ties and Word-of-Mouth Referral Behavior. The Journal of Consumer Research, 14:3 (December), 350-362.

6. Dawes, Philip L. \& Jennifer Brown (2005). The Composition of Consideration and Choice Sets in Undergraduate University Choice: An Exploratory Study. Journal of Marketing For Higher Education, 14:2, 2005, 37-59.

7. Engel, James E., Roger D. Blackwell, and Robert J. Kegerreis (1969), "How Information is Used to Adopt an Innovation," Journal of Advertising Research, 9 (December), 3-8.

8. Feldman, SidneyP. and Merlin C. Spencer (1965), "The Effect of Personal Influence in the Selection of Consumer Services," in Proceedings of the Fall Conference of the American Marketing Association, ed. Peter D. Bennett, Chicago: American Marketing Association, 440-452.

9. Garfield, Bob (2009). Future May Be Brighter, but It's Apocalypse Now. Advertising Age (March 23). Retrieved May 1, 2009 at http://www.newspaperdeathwatch.com/wpcontent/uploads/2009/03/chaos_scenario_for_media.pdf

10. Gillin, Paul (2007). The New Influencers: A Marketer's Guide to the New Social Media. Fresno: Linden Publishing.

11. Hoyer, Wayne D. \& Deborah J. MacInnis (2007). Consumer Behavior. Boston: Houghton Mifflin.

12. Katz, Elihu and Paul F. Lazarsfeld (1955), Personal Influence, Glencoe, IL: Free Press.

13. Marklein, Mary Beth (2009, April 29). College recruiters are Twittering, too. USA Today.

14. Richins, Marsha L. (1983). Negative Word-of-Mouth by Dissatisfied Consumers: A Pilot Study. The Journal of Marketing, 47:1 (Winter), 68-78. 
NOTES 